\title{
A Comprehensive Density-of-States Model for Oxide Semiconductor Thin Film Transistors
}

\author{
Kadiyam Rajshekar \\ Vellore Institute of Technology: VIT University \\ Kannadassan Dhanaraj ( $\nabla$ dkannadassan@vit.ac.in ) \\ Vellore Institute of Technology: VIT University https://orcid.org/0000-0001-7891-0264
}

\section{Research Article}

Keywords:

Posted Date: February 25th, 2021

DOI: https://doi.org/10.21203/rs.3.rs-236642/v1

License: (c) (i) This work is licensed under a Creative Commons Attribution 4.0 International License. Read Full License

Version of Record: A version of this preprint was published at Journal of Computational Electronics on November 1st, 2021. See the published version at https://doi.org/10.1007/s10825-021-01783-8. 


\title{
A Comprehensive Density-of-States Model for Oxide Semiconductor Thin Film Transistors
}

\section{Kadiyam Rajshekar ${ }^{1}$ and D. Kannadassan ${ }^{2 *}$}

1. School of Electronics Engineering, Vellore Institute of Technology, Vellore - 632014, India.

2. Centre for Nanotechnology Research, Vellore Institute of Technology, Vellore - 632014, India.

*Corresponding author: D. Kannadassan, email: dkannadassan@vit.ac.in

\begin{abstract}
In this paper, a comprehensive Density of States model was proposed to understand the origin of conductivity and the performance of p-type and n-type oxide semiconductor thin film transistors (TFTs). To validate the model, the simulated I-V characteristics are compared with measured results of p-type $\mathrm{Cu}_{2} \mathrm{O} \& \mathrm{SnO}$ and n-type $\mathrm{SnO}_{2}$ TFTs. It was found that cation vacancies were responsible for hole conduction in p-type TFTs, while anion vacancies and/or metal interstitial were responsible for electron conduction in n-type TFTs. This was observed by assigning the cation vacancies to acceptor-like Gaussian states and anion vacancies and/or metal interstitial to Donor-like Gaussian states respectively. The characteristic slopes in conduction/valence band-tail states are due to disorders present in the oxide semiconductors. The model is successfully delivering the physical insight and path way to circuit simulation of large scale integration of pixel circuits AMLCD/AMOLED displays.
\end{abstract}

\section{Introduction}

Oxides Semiconductor (OS) thin film transistors (TFTs) have emerged as an important technology in transparent electronics and opto-electronic display devices while comparing polySi and amorphous silicon TFTs [1]. OSs show remarkably high field-effect mobility, wide bandgap and high uniformity over larger areas [2]. These properties help in development of many high performance display technologies, such as active matrix LCDs (AMLCD) and active matrix OLEDs (AMOLED) [3]. In the past few years, display industries have transpired into a multibillion-dollar business market, expected to reach $\$ 87.2$ billion by the year 2025 [1]. Recently, display industries, such as Samsung, LG and Sharp, have already claimed the making of 70" ultradefinition (UD) 3D-TVs with high scanning frequency of $240 \mathrm{~Hz}$ [1]. Due to room temperature fabrication capability of OSs [4], flexible electronics are becoming the future applications which are thinner, lighter and easier to carry [5]. Apart from displays, oxide semiconductors have still been used in other applications like solar cells, electrochromic windows, invisible security circuits, gas sensors, memory device etc. [6][7].

Backpanels for AMLCD/AMOLEDs often use n-type TFTs with indium tin oxide [8] and amorphous indium gallium zinc oxide (a-IGZO) [9]. It is due to their high field effect mobility of 
$>10 \mathrm{~cm}^{2} \mathrm{~V}^{-1} \mathrm{~s}^{-1}$ and high ON/OFF current ratio of $>10^{7}$ [1]. Yet, CMOS transistors result an improved switching characteristics with architectural simplicity which offers a logic voltage swing with $>85 \%$ of high output voltage [10]. Therefore, they demand an efficient p-type OSs for future high-speed and high-density displays. Few metal oxides are native p-type OSs, such as $\mathrm{Cu}_{2} \mathrm{O}$ and $\mathrm{SnO}$, however they show limited effective mobility due to restrictions in localized O $2 p$ orbitals of valence band [11].

CAD based numerical simulation tools, such technology-CAD (TCAD), are often used to design and analyse the semiconductor device and circuits. They use physical models to describe the carrier transport, reaction for external electrical signals and optical nature of semiconductor devices. Although oxide semiconductors have been known for over five decades [12], still major debate persists about the source of conductivity. This makes them being one today's least known semiconductor groups. It is due to the lack of understanding of the microscopic nature of the amorphous oxides. In particular, the development of defects in the generation of carriers and carrier localization behavior, are far from fully known. Therefore, the properties of carrier transport such as mobility and scattering phenomena are also need detailed study.

This paper presents a comprehensive physical model of density-of-states (DOS) in oxide semiconductors. The model is proposed to incorporate the device modeling in TCAD tools. The validity of the proposed model is addressed with measured results of early reports. The model helps to investigate the influence of various defects on carrier transport mechanism and device performance. In following sections, we have presented the development of comprehensive DOS model of OS. Based on the model, in section III, we simulated $\mathrm{Cu}_{2} \mathrm{O}, \mathrm{SnO}$ and $\mathrm{SnO}_{2}$ TFTs to study the I-V characteristics. The physics and origin of the device performance using DOS model are discussed in detail. This physical model of OS helps device engineers and industries to design and optimize the high performance transparent electronic circuits.

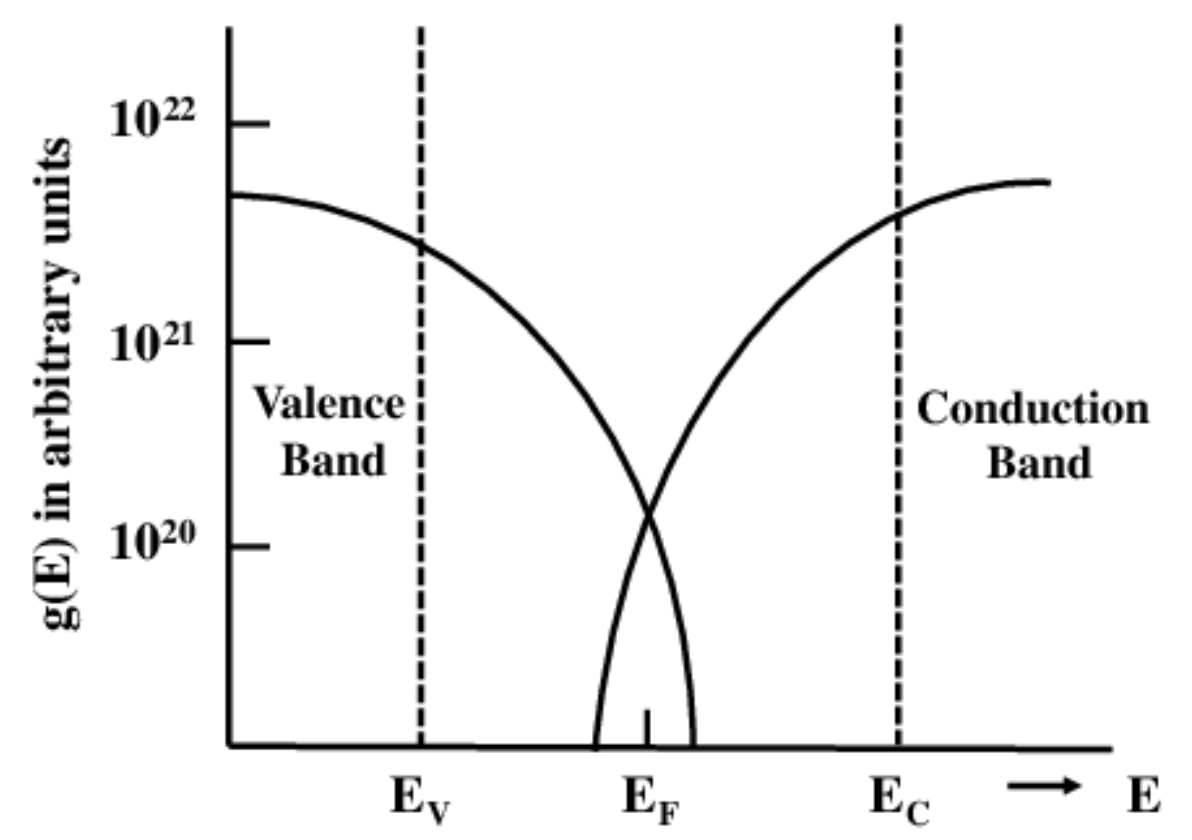

Figure 1: A simple two tail state model for amorphous semiconductors (Cohen Model) [13] 


\section{Density of States for Oxide Semiconductor}

Defects control optical and electronic properties of OS and play a crucial role in the reaction of the material to external stimulus. In general, any divergence from the ideal crystalline lattice is a defect. It could be a point defect like interstitial or vacancy, an impurity or an extended defect such as stacking fault or dislocation. In OS material, these defects and disorders are intrinsically available, leads to the spreading of electronic state $g(E)$ into the forbidden states, often referred as tail states, shown in Fig. 1.

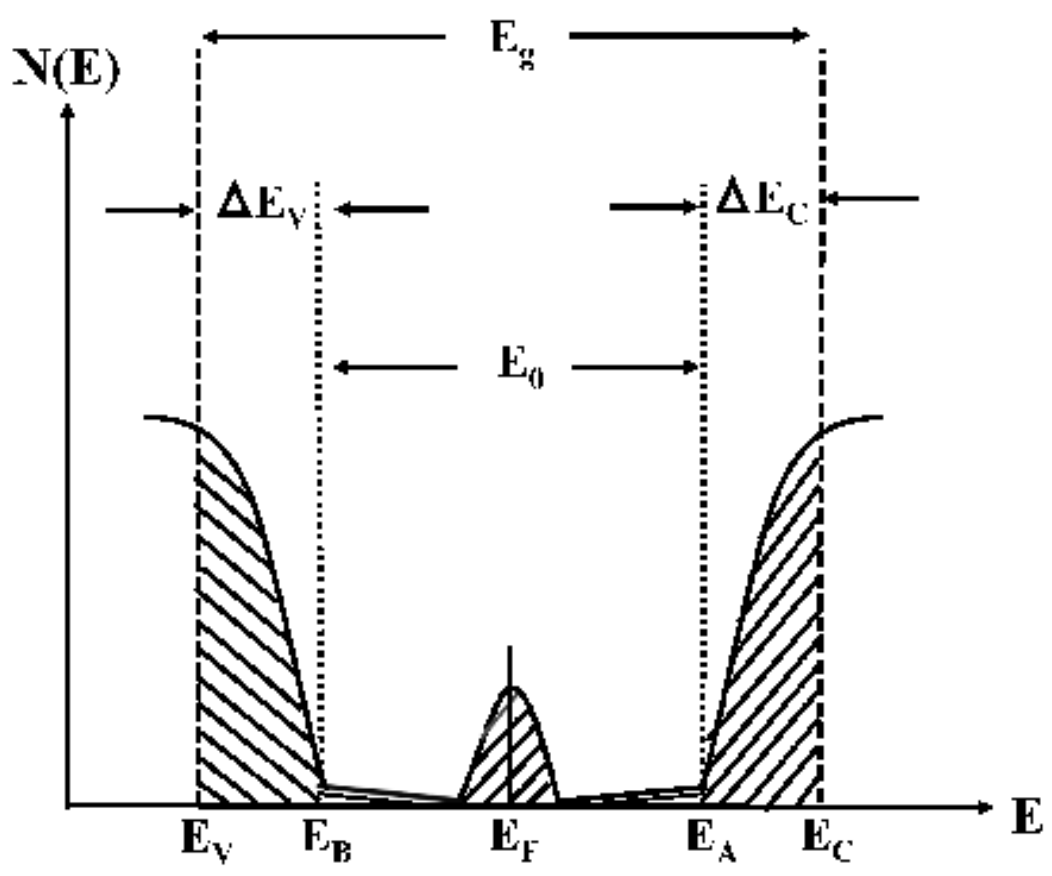

Figure 2: Improvised band model for amorphous semiconductors (Davis model) [14].

Theoretical interpretation of tail states in OS was explained by various researchers. Cohen et al., in the year 1969 [13], explained the properties the amorphous semiconductor alloys through a simple band model. The model presumes the presence of sharp mobility edges $E_{C}$ and $E_{V}$, separates the extended and localized states in both conduction and valence bands respectively. In this model, the density of conduction and valence band tail states are extended with in the band gap and overlap each other as shown in Fig. 1. It is worth to note that, the mobility in the extended states (delocalized states) is considerably large in comparison with localized states. Later, Cohen model was compared with the measured DOS at $\left(\mathrm{E}=\mathrm{E}_{\mathrm{F}}\right)$ for chalcogenide glass [15]. It was found that $\mathrm{g}(\mathrm{E})$ was in the order of $10^{19} \mathrm{~cm}^{-3} \mathrm{eV}^{-1}$. However, the model could not explain the well-defined localization states of elemental and compound amorphous semiconductors.

Later, the model was improvised by Davis et al., [14]. They had separated the energy range for localized tails states for $\mathrm{CB}$ and $\mathrm{VB}$ by introducing $\Delta \mathrm{E}_{\mathrm{C}}\left(\mathrm{E}_{\mathrm{C}}-\mathrm{E}_{\mathrm{A}}\right)$ and $\Delta \mathrm{E}_{\mathrm{V}}\left(\mathrm{E}_{\mathrm{B}}-\mathrm{E}_{\mathrm{V}}\right)$ respectively, as shown in Fig. 2. In addition to this, they assumed a band of localized state at the middle of the forbidden band. Regardless of amorphous nature in OS, they exhibit good electrical properties, 
particularly a high electron mobility of $>50 \mathrm{~cm}^{2} \mathrm{~V}^{-1} \mathrm{~s}^{-1}[16]$. The conduction band minimum (CBM) holds the electron-transport path which consists of overlapped $s$ orbitals of spherical shape metal cations. This creates a conducting path for free electrons, provided by oxygen vacancies, with small effective mass [4][17]. This in-turn increases the electron mobility. However, achieving such a high mobility for holes is difficult. This is due to their transport path in VBM (valence-band maximum), which comprises of localized oxygen $2 p$ Orbitals. That makes holes heavier and results low mobility. Also, the creation of hole is hindered by the high formation energy of the cation vacancies, which are native acceptors.

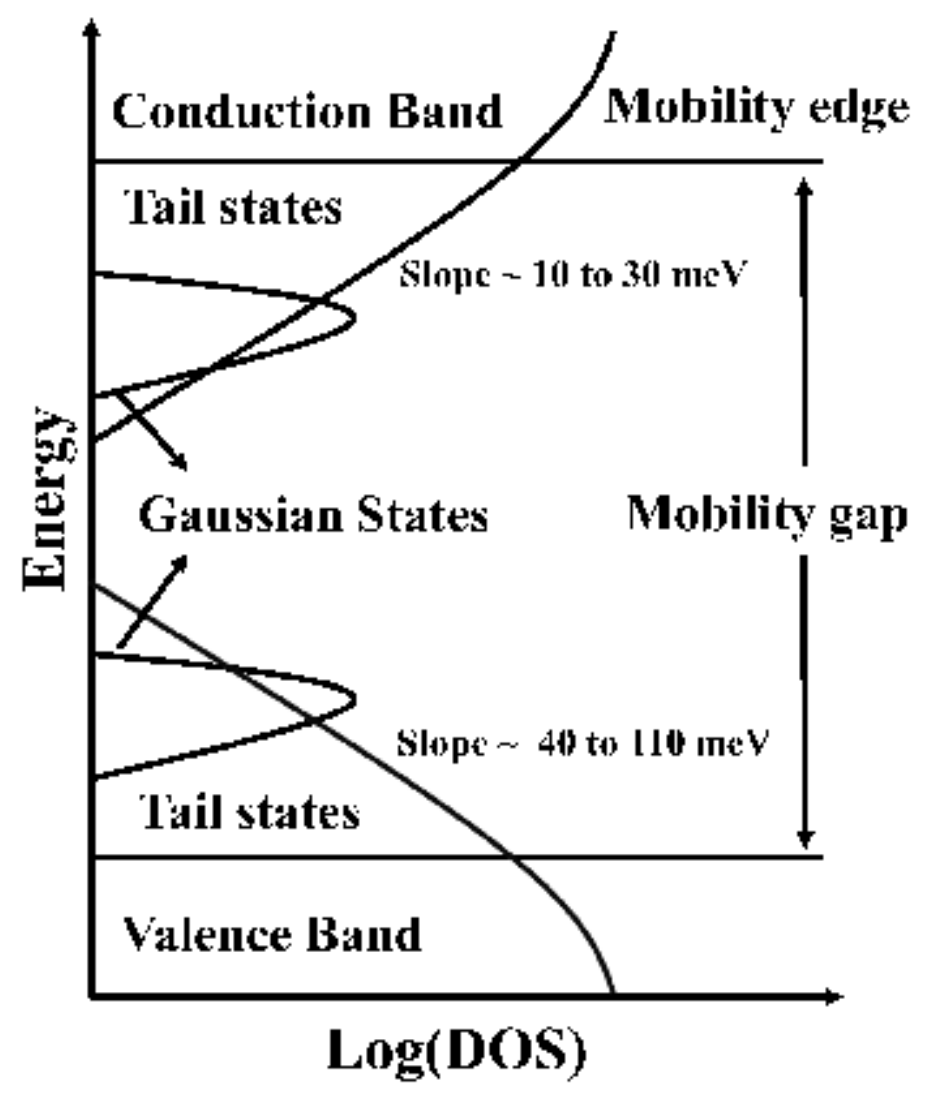

Figure 3: Proposed comprehensive DOS Model for oxide semiconductors

Based on the observations from disorders and defects in OS, a comprehensive DOS model was proposed as shown in Fig. $\underline{3}$, which summarize all effects. The model has exponentially declining states called as band tails states and deep-level sub-band mid gap states also called Gaussian states. These states are presented as schematic in Fig. $\underline{3}$. It is necessary to identify the origins of these states that contribute to DOS model.

The spherical $s$-orbitals in CB are immune to structural disorders. Due to this, the n-type OS show smaller tails in the CB. On the other hand, the O $2 p$ orbitals near VBM are highly affected by direction dependent disorders. This results larger tail tails in the VB [4][18]. Considering these facts, the tail states of $\mathrm{CB}$ and $\mathrm{VB}$ are described as

$$
\begin{aligned}
& G_{T A}(E)=g_{T A}(E) e^{\frac{\left(E-E_{C}\right)}{U_{T A}}} \\
& G_{T D}(E)=g_{T D}(E) e^{\frac{\left(E_{V}-E\right)}{U_{T D}}}
\end{aligned}
$$


where $\mathrm{E}$ is the trap energy. $\mathrm{G}_{\mathrm{TA}}(\mathrm{E})$ (acceptor-like states) and $\mathrm{G}_{\mathrm{TD}}(\mathrm{E})$ (donor-like states) are exponential decaying tail states with respect to the conduction band edge densities $\left(\mathrm{g}_{\mathrm{TA}}(\mathrm{E})\right)\left(/ \mathrm{cm}^{3}\right.$ $\mathrm{eV})$ at $\mathrm{E}=\mathrm{E}_{\mathrm{C}}$ and valence band edge densities $\left(\mathrm{g}_{\mathrm{TD}}(\mathrm{E})\right)\left(/ \mathrm{cm}^{3} \mathrm{eV}\right)$ at $\mathrm{E}=\mathrm{EV}_{\mathrm{V}}$. $\mathrm{U}_{\mathrm{TA}}$ and $\mathrm{U}_{\mathrm{TD}}$ are characteristics slopes of $\mathrm{g}_{\mathrm{TA}}$ and $\mathrm{g}_{\mathrm{TD}}$ respectively. These slopes signify the disorder present in the material.

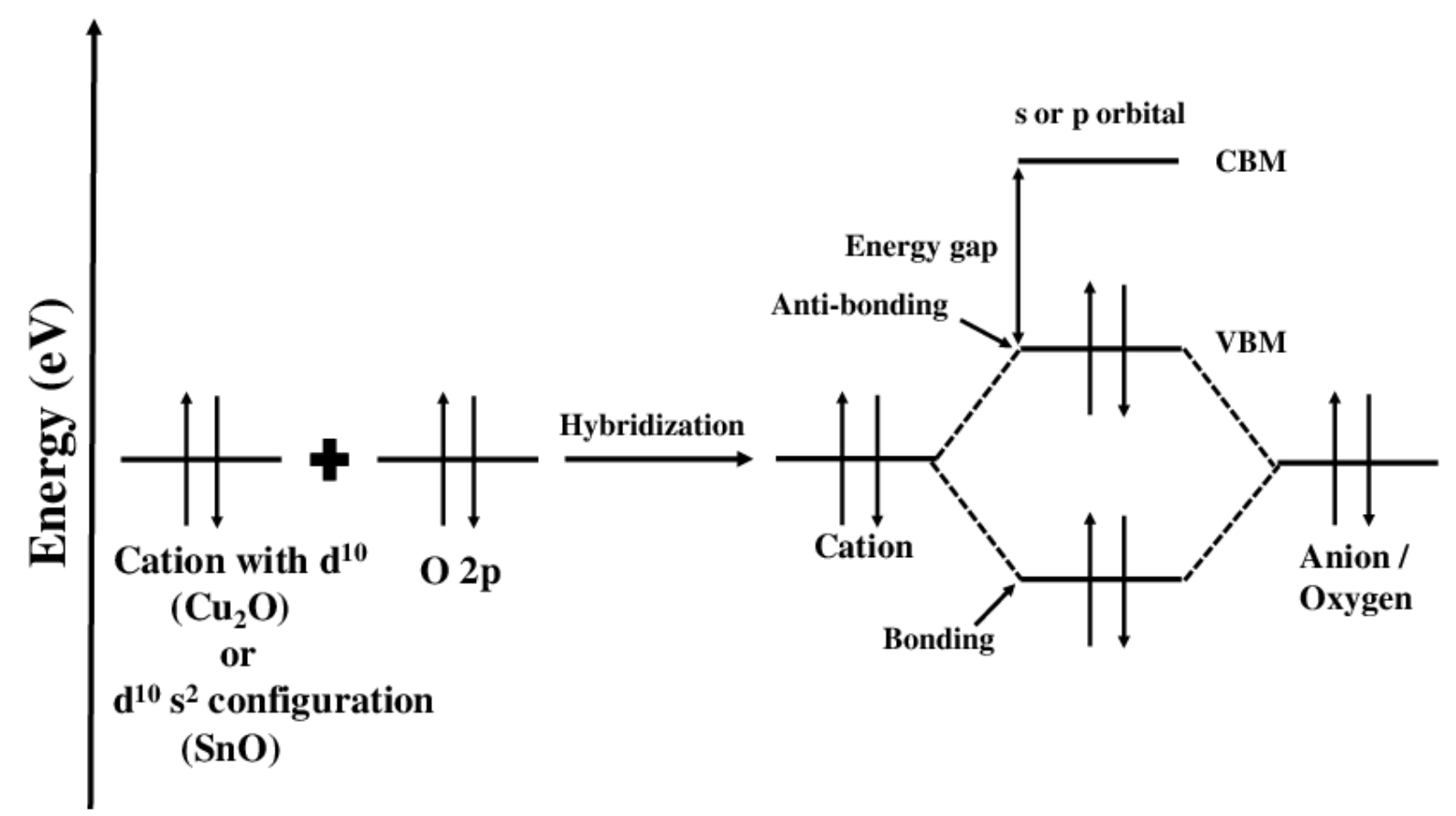

Figure 4: Chemical modulation of Valence Band between closed or pseudo closed metal configuration and an oxide ion [21].

Deep states or Gaussian states are induced in the OS due to large divergence in the coordination number as compared with crystalline one, such as vacancies. At the lower half of the band gap, below the $\mathrm{E}_{\mathrm{F}}$, the Gaussian state are present due to the variation of coordination number of oxygen atoms [19]. Similarly, miscoordinated cations were recommended to be the source of deep states in the upper half of the forbidden band [20]. These states shall be described as

$$
\begin{gathered}
G_{G A}(E)=g_{G A}(E) e^{\left[\frac{-\left(E_{G A}-E\right)^{2}}{U_{G A}^{2}}\right]} \\
G_{G D}(E)=g_{G D}(E) e^{\left[\frac{-\left(E-E_{G D}\right)^{2}}{U_{G D}^{2}}\right]}
\end{gathered}
$$

Here, $\mathrm{G}_{\mathrm{GA}}(\mathrm{E})$ and $\mathrm{G}_{\mathrm{GD}}(\mathrm{E})$ are acceptor-like and donor-like mid-gap states with their respective Gaussian distribution densities $g_{G A}$ and $g_{G D}$ with peak energies $E_{G A}$ and $E_{G D}$ respectively. $U_{G A}$ and $\mathrm{U}_{\mathrm{GD}}$ are characteristics slopes of $\mathrm{g}_{\mathrm{GA}}$ and $\mathrm{g}_{\mathrm{GD}}$ respectively.

The total DOS, $\mathrm{G}(\mathrm{E})$ can be written as:

$G(E)=G_{T A}(E)+G_{T D}(E)+G_{G A}(E)+G_{G D}(E)$ 
The DOS model was essentially first developed for amorphous hydrogenated silicon (a$\mathrm{Si}: \mathrm{H})$ material based thin film transistors (TFTs), demonstrated by Davis et al., [14]. Later, the model was extended for amorphous Indium Gallium Zinc oxides (a-IGZO) based TFTs by Fung et al [22] which gives a very high performance compared to a-Si:H TFTs.
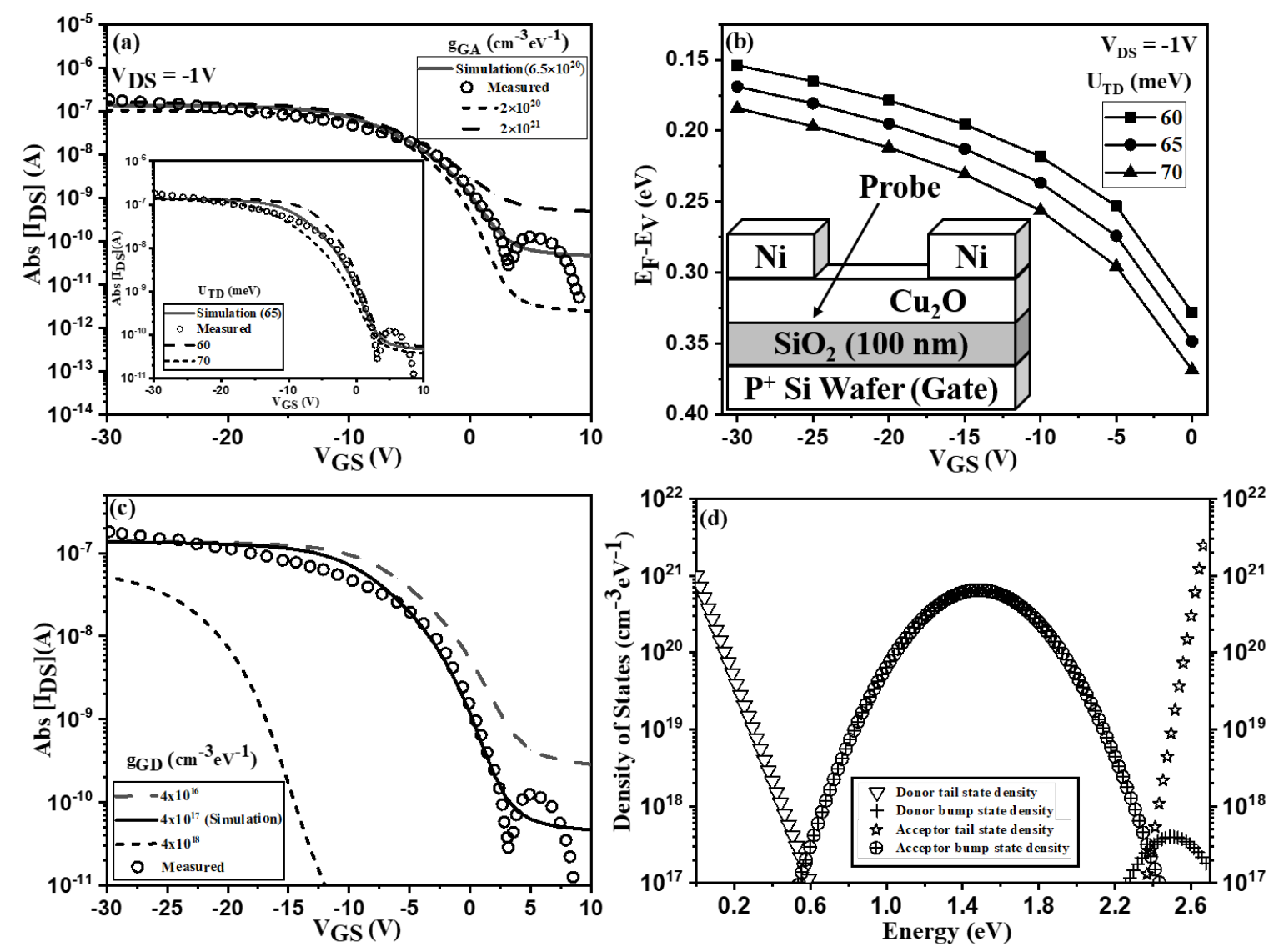

Figure 5: (a) Compatibility of simulated transfer characteristics of $\mathrm{Cu}_{2} \mathrm{O}$ TFTs for various $\mathrm{g}_{\mathrm{GA}}$ with measured results (Inset: variation in $\mathrm{U}_{\mathrm{TD}}$ ), (b) Effect of VGS on ( $\mathrm{E}_{\mathrm{F}}-\mathrm{E}_{\mathrm{V}}$ ) at the probe (Inset: Structure of $\mathrm{Cu}_{2} \mathrm{O}$ TFT), (c) Compatibility of simulated transfer characteristics of $\mathrm{Cu}_{2} \mathrm{O}$ TFTs for various $\mathrm{g}_{\mathrm{GD}}$ with measured results (d) Extracted DOS of $\mathrm{Cu}_{2} \mathrm{O}$ TFT. (Measured data: [24])

\section{Numerical simulation of OS TFTs}

CAD based numerical simulation are often used since they provide detailed physical insight of the device operation. For the simulation of TFT device, TCAD Silvaco (Atlas) tool was employed [23]. It solves the coupled equations, consists of Poisson, continuity and charge transport equations, for the given device boundary. It also allows the physics of defect states in the active layer using DOS model. The simulation was performed on staggered bottom gate TFTs. From the accuracy point of view, high density meshing has been employed near the active layer/dielectric interface along Y-axis. Necessary models like field-dependent mobility, defect model, FermiDirac model and interface trap model were applied to the active layer. Along with that, boundary conditions were set for the active layer to regulate the carrier movement within the source and drain electrode. Moreover, for electrodes, tunneling and thermionic models, along with ohmic 
contact models were also used. Discrete DOS model, consists of acceptor-like (ACC) and donorlike (DON) with 128 traps states each respectively were employed for the simulation. Using this simulation setup, we have simulated the cuprous oxide $\left(\mathrm{Cu}_{2} \mathrm{O}\right)$, tin monoxide $(\mathrm{SnO})$, and tin oxide $\left(\mathrm{SnO}_{2}\right)$ based TFTs with the comprehensive DOS model.

Table 1: Key simulation parameters in DOS model for $\mathrm{Cu}_{2} \mathrm{O}, \mathrm{SnO}$ and $\mathrm{SnO}_{2}$ TFTs respectively.

\begin{tabular}{|l|l|l|l|l|}
\hline Symbols & Units & $\mathrm{Cu}_{2} \mathrm{O}$ & $\mathrm{SnO}$ & $\mathrm{SnO}_{2}$ \\
\hline $\mathrm{N}_{\mathrm{C}}$ & $\mathrm{cm}^{-3}$ & $2.47 \times 10^{19}$ & $2.41 \times 10^{18}$ & $3.51 \times 10^{18}$ \\
\hline $\mathrm{N}_{\mathrm{V}}$ & $\mathrm{cm}^{-3}$ & $1.11 \times 10^{19}$ & $9.13 \times 10^{19}$ & $1.13 \times 10^{19}$ \\
\hline $\mathrm{g}_{\mathrm{TA}}$ & $\mathrm{cm}^{-3} \mathrm{eV}^{-1}$ & $2.47 \times 10^{21}$ & $2.43 \times 10^{20}$ & $1 \times 10^{20}$ \\
\hline $\mathrm{g}_{\mathrm{TD}}$ & $\mathrm{cm}^{-3} \mathrm{eV}^{-1}$ & $1 \times 10^{21}$ & $5 \times 10^{20}$ & $1.13 \times 10^{21}$ \\
\hline $\mathrm{U}_{\mathrm{TA}}$ & $\mathrm{meV}$ & 30 & 30 & 20 \\
\hline $\mathrm{U}_{\mathrm{TD}}$ & $\mathrm{meV}$ & 65 & 70 & 40 \\
\hline $\mathrm{E}_{\mathrm{g}}$ & $\mathrm{eV}$ & 2.7 & 0.9 & 3.6 \\
\hline$\chi_{\mathrm{e}}$ & $\mathrm{eV}$ & 3 & 3.7 & 4 \\
\hline $\mathrm{U}_{\mathrm{GA}}$ & $\mathrm{eV}$ & 0.32 & 0.1 & 0.1 \\
\hline $\mathrm{E}_{\mathrm{GA}}$ & $\mathrm{eV}$ & 1.5 & 0.52 & 0.8 \\
\hline $\mathrm{E}_{\mathrm{GD}}$ & $\mathrm{eV}$ & 2.5 & 0.9 & 3.3 \\
\hline $\mathrm{U}_{\mathrm{GD}}$ & $\mathrm{eV}^{-3}$ & 0.2 & 0.2 & 0.25 \\
\hline $\mathrm{g}_{\mathrm{GD}}$ & $\mathrm{cm}^{-3} \mathrm{eV}^{-1}$ & $4 \times 10^{17}$ & $1 \times 10^{17}$ & $1.3 \times 10^{18}$ \\
\hline $\mathrm{g}_{\mathrm{GA}}$ & $\mathrm{cm}^{-3} \mathrm{eV}^{-1}$ & $6.5 \times 10^{20}$ & $2 \times 10^{19}$ & $2 \times 10^{16}$ \\
\hline$\mu_{\mathrm{P}}$ & $\mathrm{cm}^{2} \mathrm{~V}^{-1} \mathrm{~s}^{-1}$ & 47.5 & 4.8 & 18.6 \\
\hline$\epsilon$ & & 7.6 & 15 & 9 \\
\hline
\end{tabular}

\subsection{P-type $\mathrm{Cu}_{2} \mathrm{O}$ and $\mathrm{SnO}$ TFTs}

In general, the p-type OSs are rare due to dominant $\mathrm{O} 2 p$ orbitals which strongly localized the hole and restricts p-type conduction. To overcome this problem, Kawazoe et al., proposed an alternative way to reduce the localization of $2 p$ orbitals known as "Chemical modulation of Valence band" [21]. In this approach, $2 p$ orbital undergoes hybridization with metal $d$ or $s$ orbitals of equivalent energy levels. This results the formation of extended valence band in the form of bonding and anti-bonding levels. This shifts the valence band edge to anti-bonding level from $\mathrm{O}$ $2 p$ level due to the closed shell electronic configuration of both cations and anions. The modification of band diagram in VB largely helps to reduce the localization of holes, and hence improves the hole mobility with in the material. This phenomenon is shown in the Fig. 4. Based

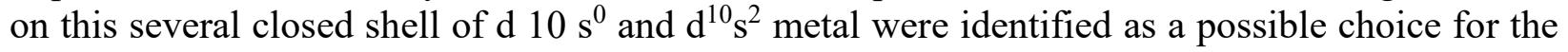
development of p-type OS [25][26]. 
Cuprous oxide, $\mathrm{Cu}_{2} \mathrm{O}\left(\mathrm{Cu}^{\mathrm{I}}\right)$ was recognized as potential candidate, since it has closed $\mathrm{d}^{10}$ shell whose energy is comparable with oxygen $2 p$ orbital energy [25]. Due to cation-deficient, it acts as p-type (hole conduction). It has simple cubic structure with a lattice constant of $4.27 \AA$. Generally, copper oxide system at fixed metal-oxide ratio (stoichiometry) got two stable phases $\left(\mathrm{Cu}_{2} \mathrm{O}\right.$ and $\left.\mathrm{CuO}\right)$ and one meta-stable phase paramelaconite $\left(\mathrm{Cu}_{4} \mathrm{O}_{3}\right)$. However, during the synthesis process like sputtering, copper oxide system becomes non-stoichiometry due to copper vacancies. This gives an opportunity to tune the electronic properties of semiconducting $\mathrm{Cu}_{2} \mathrm{O}$ by varying oxygen partial pressure of the deposition scheme.
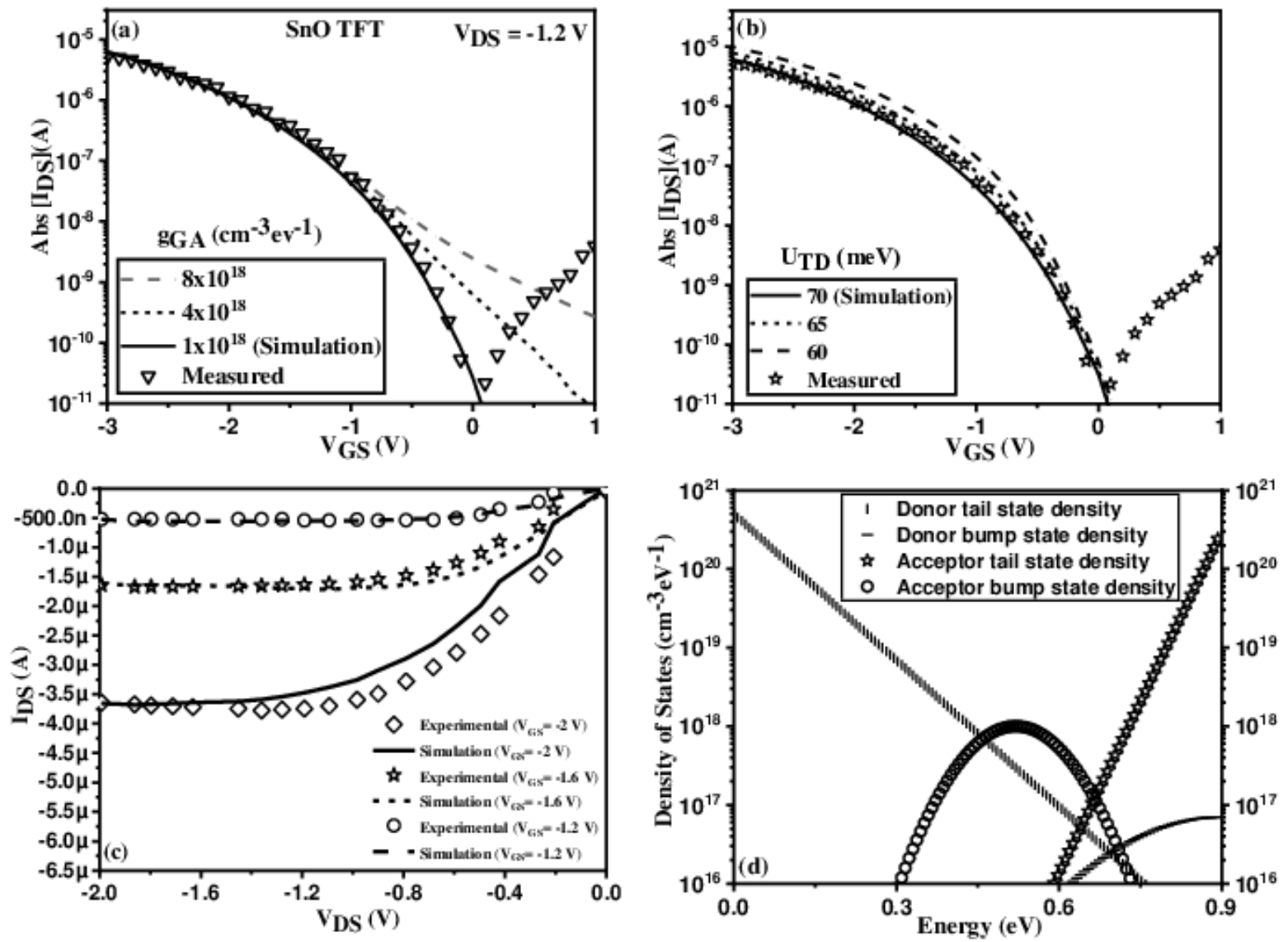

Figure 6: (a) Compatibility of simulated transfer characteristics of SnO TFTs for various $\mathrm{g}_{\mathrm{GA}}$ with measured results, (b) Compatibility of simulated transfer characteristics of SnO TFTs for various $g_{G D}$ with measured results, (c) Simulated output characteristics with measured results (d) Extracted DOS of SnO TFT. (Measured data: [29])

To analyze further, first-principle density functional theory (DFT) simulations were performed which offers valuable insight of defects with various functionality [27]. This helps to compute the formation energy and the transition phase of defects, which influences the electronic structures and hence affects the electrical and optical properties of the system. From the simulation, it was found that the cations deficiency is due to copper vacancies $\left(\mathrm{V}_{\mathrm{Cu}}\right)$. These defects have lowest formation energies under both $\mathrm{Cu}$-rich and $\mathrm{Cu}$-poor conditions [25]. The VBM, which mostly consists of $\mathrm{Cu}^{(\mathrm{I})}\left(\mathrm{d}^{10}\right)$ orbitals, is an anti-bonding state. Its acceptor ionization energy or transition level $\varepsilon(0 /-1)$ is located at $\mathrm{E}_{\mathrm{V}}+0.28 \mathrm{eV}$, which is relatively shallow. Covalency property allows band 
broadening that leads to small effective mass and finally gets good carrier mobility [21]. Based on the several literature, $\mathrm{Cu}_{2} \mathrm{O}$ has shown a remarkable hall mobility of $>100 \mathrm{~cm}^{2} \mathrm{~V}^{-1} \mathrm{~s}^{-1}$ [28]. Although several computational and experimental works on defects of $\mathrm{Cu}_{2} \mathrm{O}$ systems, there are no reports on the modeling of p-type conduction using DOS model. This can be addressed by adopting the proposed DOS model in numerical simulation to fit the measured I-V characteristics of fabricated $\mathrm{Cu}_{2} \mathrm{O}$ TFTs.

In 2012, Nam et al., have reported the fabrication and characterization of p-type $\mathrm{Cu}_{2} \mathrm{O}$ TFT using RF magnetron sputtering [24]. On a heavily doped p-type Si substrate, act as gate electrode, a $100 \mathrm{~nm} \mathrm{SiO}_{2}$ dielectric was thermally grown. Thereafter, a $45 \mathrm{~nm}$ thin film of $\mathrm{Cu}_{2} \mathrm{O}$ was deposited using RF magnetron sputtering followed by annealing at $500{ }^{0} \mathrm{C}$ for 7 minutes. Subsequently, using evaporation technique Ni contacts were deposited and patterned as source and drain with channel width and length of $1000 \mu \mathrm{m}$ and $100 \mu \mathrm{m}$ respectively. A realistic simulation of $\mathrm{Cu}_{2} \mathrm{O}$ TFT was performed with device structure shown in Fig. $\underline{5}$ (b) inset. For the fitting of transfer characteristics, initially noted physical parameters like effective mass of electron and holes $\left(\mathrm{m}_{\mathrm{C}}=0.98 \mathrm{~m}_{0}\right.$ and $\left.\mathrm{m}_{\mathrm{V}}=0.66 \mathrm{~m}_{0}\right)$ [30], band hole mobility $\left(47.5 \mathrm{~cm}^{2} \mathrm{~V}^{-1} \mathrm{~s}^{-1}\right)$ [24] are considered. The details of the input parameters are listed in the Table 1 .

For the simulation of TFT, there are few key DOS parameters which significantly influences the I-V characteristics TFTs. These parameters are $\mathrm{g}_{\mathrm{GA}}, \mathrm{g}_{\mathrm{GD}}, \mathrm{U}_{\mathrm{TA}}$ and $\mathrm{U}_{\mathrm{TD}}$. Based on the first principle study by Raebiger et al., [25], it was found that $\mathrm{Cu}_{2} \mathrm{O}$ exhibits p-type conduction due to the presence of copper vacancies $\left(\mathrm{V}_{\mathrm{Cu}}\right)$. These are acceptor-like vacancies which are present near to the VBM. In simulation, we have imitated $\mathrm{V}_{\mathrm{Cu}}$ with $\mathrm{g}_{\mathrm{GA}}$ parameter. Fig. $\underline{5}$ (a) shows the effect of $g_{\mathrm{GA}}$ on the simulated I-V characteristics. As the $\mathrm{g}_{\mathrm{GA}}$ value increases, the OFF current of $\mathrm{Cu}_{2} \mathrm{O}$ TFT increases. This is due to the presence of more acceptor-like vacancies $\left(\mathrm{V}_{\mathrm{Cu}}\right)$, which could allow more hole current to flow across the channel. In reference to Raebiger et al., the concentration of $\mathrm{g}_{\mathrm{GA}}$ is quite comparable with the $\mathrm{V}_{\mathrm{Cu}}$, which is above $10^{20} \mathrm{~cm}^{-3} \mathrm{eV}^{-1}$. However, the change in the $\mathrm{ON}$ current due to $\mathrm{g}_{\mathrm{GA}}$ is small. Similarly, $\mathrm{U}_{\mathrm{TD}}$ parameter was varied from 60 to $70 \mathrm{meV}$ and it was found that there are substantial changes in the drain current (inset Fig. $\underline{5}$ (a)). To understand this phenomena, a probe was put up near the active/dielectric interface layer the computed $\left(E_{F}-E_{V}\right)$ as a function of $V_{G S}$ is plotted for different $U_{T D}$, shown in the Fig. $\underline{5}$ (b). We can see as $U_{T D}$ reduces, the Fermi energy, $E_{F}$ approaches $E_{V}$ which indicates the band bending phenomena. Moreover, $\mathrm{U}_{\mathrm{TD}}$ also signifies the disorders present in the material. These disorders are due to variation in the bond angle, bond lengths and coordination numbers present in the active layer. This causes rise to the tail states with exponential distribution $\left(\mathrm{U}_{\mathrm{TD}}\right)$, also called as Urbach energy [31].

Like hole producers $\left(\mathrm{V}_{\mathrm{Cu}}\right)$, there are potential hole neutralizer in $\mathrm{Cu}_{2} \mathrm{O}$ in the form of oxygen vacancies $\left(\mathrm{V}_{\mathrm{O}}\right)$ and copper interstitial $\left(\mathrm{Cu}_{\mathrm{i}}\right)$ [25]. However, the formation energy $\Delta \mathrm{H}$ is very high in the case of $\mathrm{Cu}_{\mathrm{i}}$, so we have not consider the effect of $\mathrm{Cu}_{\mathrm{i}}$ in the simulation [25]. Like $\mathrm{V}_{\mathrm{Cu}}, \mathrm{V}_{\mathrm{O}}$ also has low formation energy which can affect the hole carrier concentration. Since oxygen vacancies contributes to giving away the electrons, hence they are donor-like states. In our simulation, we relate $V_{O}$ with $g_{G D}$. Fig. $\underline{5}$ (c) shows the simulated transfer characteristics for different $g_{G D}$. We can observe that higher values of $g_{G D}$ have significantly affect the hole current. The concentration of $\mathrm{g}_{\mathrm{GD}}$ is lower than $\mathrm{g}_{\mathrm{GA}}$ by an order of $\sim 3$ magnitude based on the literature [25]. However, the DOS parameter, $\mathrm{U}_{\mathrm{TA}}$ does not affect the hole current in any manner. Fig. $\underline{5}$ (a) and (d) shows the fitted I-V characteristics with experimental data [24] and DOS profile extracted for the same respectively. 
An alternative approach for the hybridization of $\mathrm{O} 2 p$ orbitals is to use electronic structure having pseudo closed shell configuration as shown in the Fig. 4 [26], for instance, tin monoxide $(\mathrm{SnO})$, beryllium oxide $\left(\mathrm{Bi}_{2} \mathrm{O}_{3}\right)$ and lead oxide $(\mathrm{PbO})$. Amongst these, SnO shows promising results in terms of p-type conductivity [32]. SnO exhibits tetragonal layer crystal structure and the formation of $\mathrm{Sn}-\mathrm{O}-\mathrm{Sn}$ layer is in $<011>$ direction. At VB, there is a significant overlap between $\mathrm{Sn} 5 s$ and $\mathrm{O} 2 p$ orbitals, which lead to reduction in localization of holes [33]. Several research articles were reported on SnO based p-type TFTs showing field-effect mobility $>3 \mathrm{~cm}^{2} \mathrm{~V}^{-1} \mathrm{~s}^{-1}$, ON/OFF ratio $>10^{7}$ and subthreshold swing $\sim 100 \mathrm{mV} / \mathrm{dec}$ [34]. This is largely due to the presence of $\mathrm{Sn}$ vacancies $\left(\mathrm{V}_{\mathrm{Sn}}\right)$ having low defect-formation energy which acts as a native-acceptor like defects. Its acceptor ionization energy or transition level $\varepsilon(0 /-1)$ is located at $\mathrm{E}_{\mathrm{V}}+0.1 \mathrm{eV}$. For the simulation of SnO TFT, our groups has earlier reported the fabrication and modeling SnO TFTs [34] [29].
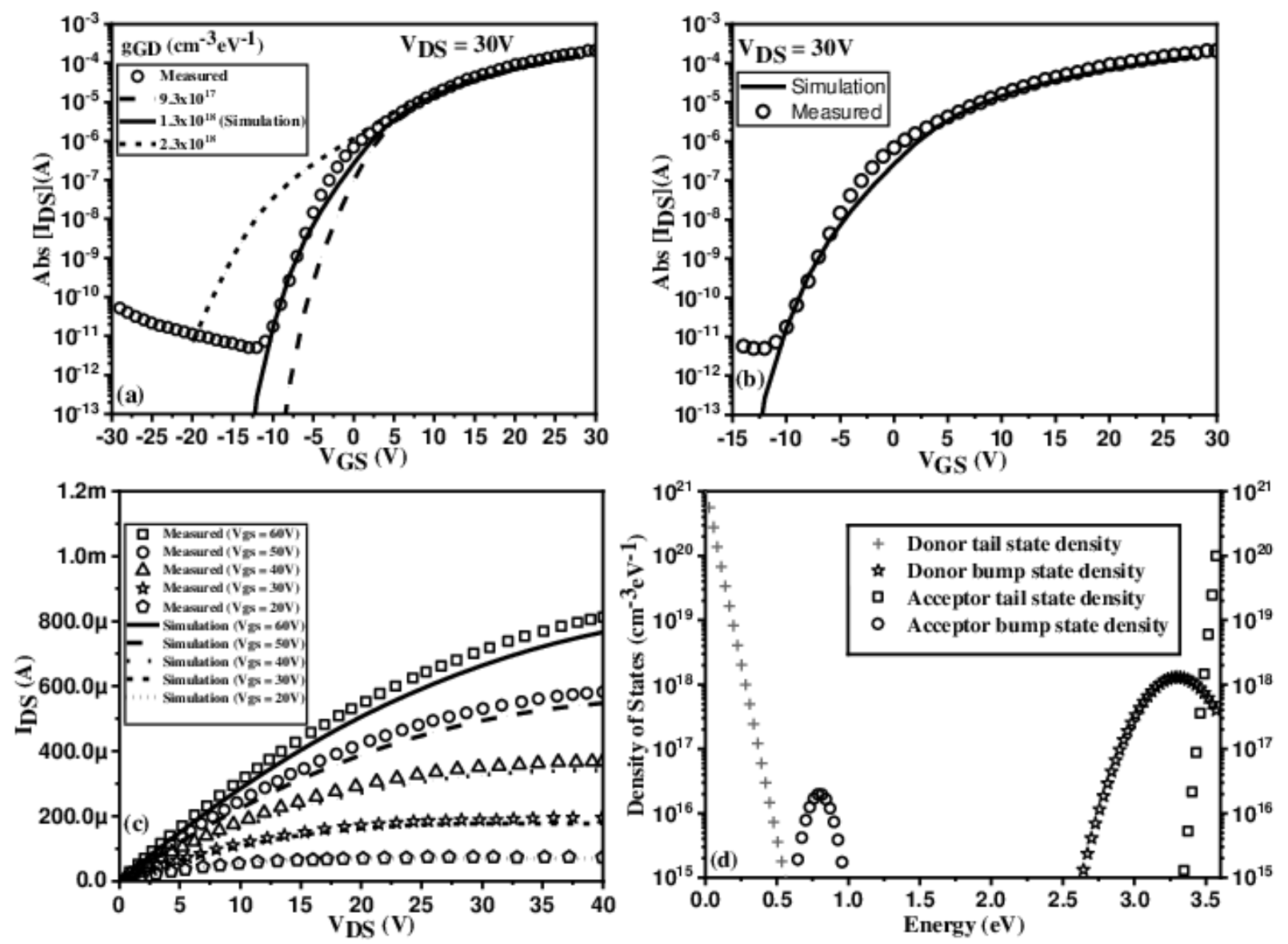

Figure 7: (a) Compatibility of simulated transfer characteristics of $\mathrm{SnO}_{2}$ TFTs for various $\mathrm{g}_{\mathrm{GD}}$ with measured results, (b) Compatibility of simulated transfer characteristics of $\mathrm{SnO}_{2}$ TFTs for various $\mathrm{g}_{\mathrm{GD}}=1.3 \times 10^{18} \mathrm{~cm}^{-3} \mathrm{eV}^{-1}$ with measured results, (c) Simulated output characteristics with measured results (d) Extracted DOS of $\mathrm{SnO}_{2}$ TFT. (Measured data: [35])

Fig. $\underline{6}(\mathrm{a})$ and (b) shows the effect of $\mathrm{g}_{\mathrm{GA}}$ and $\mathrm{U}_{\mathrm{TD}}$ on the simulated I-V characteristics of $\mathrm{SnO}$ respectively. As the $\mathrm{g}_{\mathrm{GA}}$ value increases, the OFF current of $\mathrm{SnO}$ TFT increases. This is due to the presence of more acceptor-like vacancies $\left(\mathrm{V}_{\mathrm{Sn}}\right)$, which could allow more hole current to flow across the channel [36]. Similarly, change in the $U_{T D}$, has significantly affected the drain current. 
However, the effect of $\mathrm{g}_{\mathrm{GD}}$ is minimal. This is due to the $\mathrm{V}_{\mathrm{O}}$ defect concentration which is not sufficient to neutralize the $\mathrm{V}_{\mathrm{Sn}}$ [36]. Table 1 shows the simulation parameters for SnO TFTs.

\section{$3.2 \mathrm{~N}$-type $\mathrm{SnO}_{2} \mathrm{TFTs}$}

To validate the compatibility of proposed DOS model for n-type OS, we have considered n-type tin oxide $\left(\mathrm{SnO}_{2}\right)$ based TFT. $\mathrm{SnO}_{2}$ is possibly the simplest material among OSs. It exhibits a rutile structure where each tin atom is enclosed by six oxygen atoms [37]. Again, these each oxygen atoms are surrounded by other three tin atoms. It has a direct-band gap of $3.6 \mathrm{eV}$ and oxidation state of $4\left(\mathrm{Sn}^{4+}\right)$ [37]. The n-type nature of $\mathrm{SnO}_{2}$ is due to its conduction band minimum (CBM), consists of Sn $5 s$ orbitals overlapping each other. This allows the movement electrons freely, leads to the low electron effective mass which is between 0.23 to $0.3 \mathrm{~m}_{0}$. Where $\mathrm{m}_{0}$ is the mass of electron $\left(9.1 \times 10^{-31} \mathrm{Kg} \mathrm{s}\right)$. But its valence band maximum is nearly flat, thus it has a large hole effective mass. This is due to the presence of oxygen $2 p$ states which are highly localized. Hence, it restricts hole conduction. Although, there are various reports on the successful implementation DOS model of n-type a-IGZO TFTs [22], $\mathrm{SnO}_{2}$ base TFTs are rarely modeled [38]. Saji et al., successfully demonstrated the fabrication of $\mathrm{SnO}_{2}$ TFT [35] using RF sputtering. From Sn metal target, a 25 $\mathrm{nm}$ thin film of $\mathrm{SnO}_{2}$ was deposited on the bottom Si substrate (gate electrode) using RF sputtering under different oxygen flow rate. On the top, a $100 \mathrm{~nm} \mathrm{SiO} 2$ was thermally grown followed by patterned $\mathrm{Ni} / \mathrm{Au}$ source and drain deposition using electron beam evaporation technique with channel width and length of $500 \mu \mathrm{m}$ and $500 \mu \mathrm{m}$ respectively.

Similar to $\mathrm{Cu}_{2} \mathrm{O}$ TFT, same approach was tested on $\mathrm{SnO}_{2}$ TFT for various $\mathrm{g}_{\mathrm{GD}}, \mathrm{g}_{\mathrm{GA}}, \mathrm{U}_{\mathrm{TD}}$

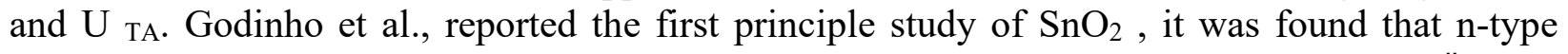
conductivity is due to the presence of doubly ionized positive charged oxygen vacancies $\left(V_{O}^{*}\right)$ [39]. According to Kröger-Vink notation the charge balance can be written as,

$O_{O}^{X} \rightarrow V_{O}^{*}+2 e^{\prime}+\frac{1}{2} O_{2}(g)$

where $O_{O}^{X}$ represents oxygen at oxygen site with neutral charge. Oxygen anions, according to this equation, escape from its oxygen site and forms $V_{O}^{*}$ with free electrons. These electrons will go to the conduction band and hence improves the current conduction. Similarly, Zunger et al, reported the low formation energies for both oxygen vacancies and tin interstitial $\left(\mathrm{Sn}_{\mathrm{i}}\right)$ contribute to n-type conduction [37]. Based on these observations, we have varied the gGD, to imitate $V_{O}^{*}$ and/or $\mathrm{Sn}_{\mathrm{i}}$, to fit the measured results. When $\mathrm{g}_{\mathrm{GD}}$ concentration increases from low to high, more electrons are induced into the $\mathrm{CB}$ which, results more drain current as shown in Fig. 7 (a). No substantial changes were observed due to the change in the $U_{\mathrm{TD}}$. This could be due to the fact that conduction band $(\mathrm{CB})$ of $\mathrm{SnO}_{2}$ is derived from $\mathrm{Sn} 5 s$ states, as they are spherically symmetrical and immune to directional dependent disorders. The same is not possible for $\mathrm{Cu}_{2} \mathrm{O}$ and $\mathrm{SnO}$, since their $\mathrm{VB}$ is derived from hybridized $\mathrm{Cu}-3 \mathrm{~d}-\mathrm{O} 2 p$ and $\mathrm{Sn} 5 \mathrm{~s}-\mathrm{O} 2 p$ respectively. This leads to large value of valence-band Urbach energy $\left(\mathrm{U}_{\mathrm{TD}}\right)$ [18]. In this perspective, achieving $\mathrm{U}_{\mathrm{TD}}$ less than $30 \mathrm{meV}$ is highly unrealistic based on the available fabrication methods for OS developments. Similarly, we have also varied the $\mathrm{g}_{\mathrm{GA}}$ which relates the $\mathrm{V}_{\mathrm{Sn}}$. However, the formation energy of $\mathrm{V}_{\mathrm{Sn}}$ is larger than the $V_{O}^{*}$, so it is highly unlikely to affect the drain current in realistic scenario [39]. In addition to this no changes were observed for different $U_{\mathrm{TD}}$ values on the drain current. Fig. 7 (b), (c) and (d) shows the fitted transfer and output characteristics with the measured data and DOS of $\mathrm{SnO}_{2}$ respectively [35]. 
Fig. $\underline{8}$ summarizes the physical modeling of OS based TFTs. It shows the probability of various defects in the material system based on their formation energy. It was found that cation vacancies were responsible for hole conduction in p-type TFTs, while anion vacancies and/or metal interstitial were responsible for electron conduction in n-type TFTs. This was observed by assigning the cation vacancies to $\mathrm{g}_{\mathrm{GA}}$ and anion vacancies and/or metal interstitial to $\mathrm{g}_{\mathrm{GD}}$ respectively.

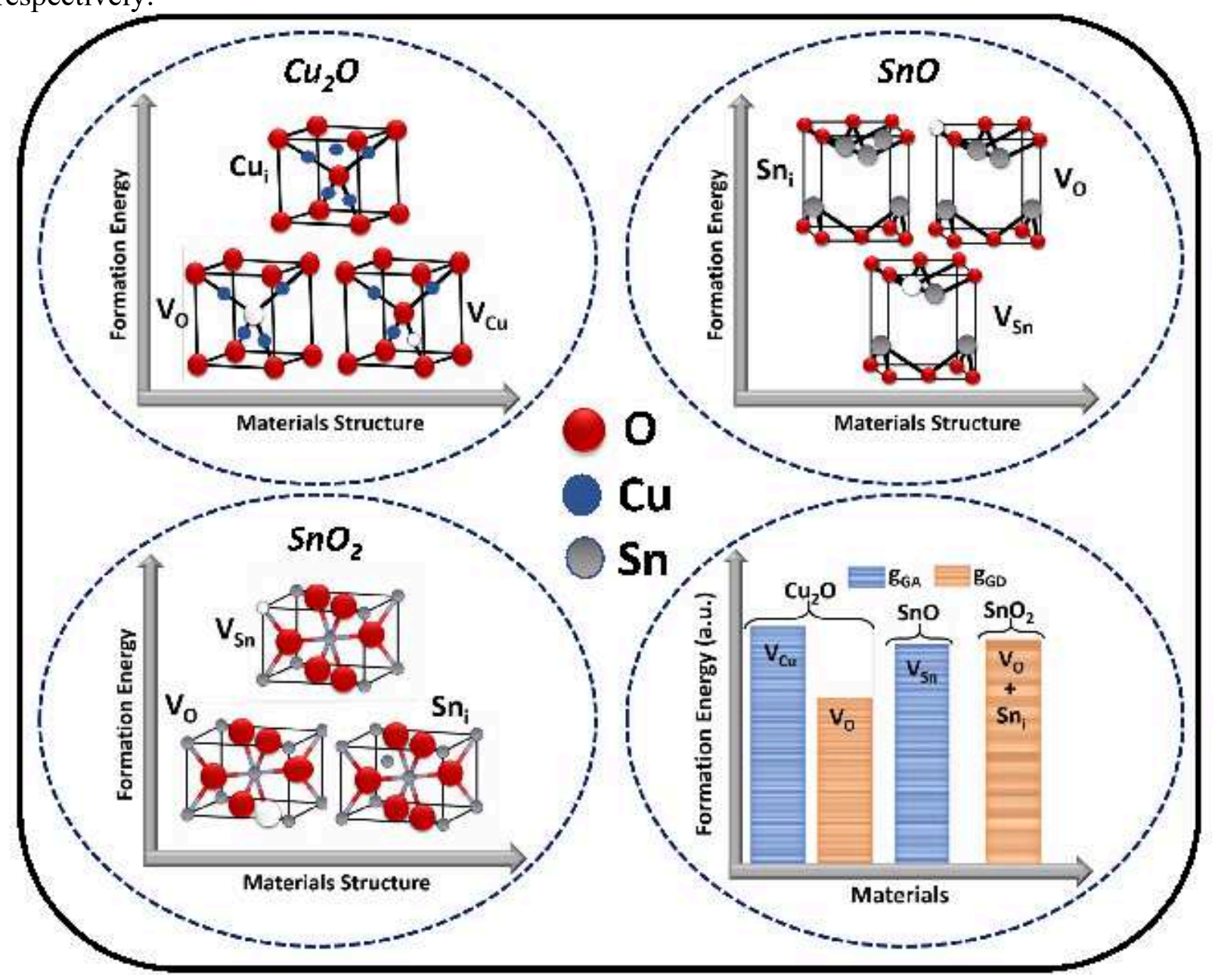

Figure 8: Summary of comprehensive physical model for various oxide semiconductor

\section{Conclusion}

This paper presents a comprehensive physical model for the TCAD based simulation of $n$ and p-type thin film transistors with oxide semiconductors. The model is developed from the earlier understanding of density of states in conduction/valance band and forbidden band gap. The model gives physics insight of carrier transport and device operation in TFTs. It was observed that the tail states due to disorders and deep states due to bulk defects of oxide semiconductors are responsible for the $\mathrm{p}$ and $\mathrm{n}$-type conductivity. The validation of the proposed model was performed by comparing the simulated I-V characteristics with measured results of p-type and n-type TFTs. An excellent fitting was observed and the density of tail and defect states are computed successfully. These understandings and specification of OS may help engineers and industries to develop high performance circuits in High-Definition displays, solar cell and flexible electronics. 


\section{Acknowledgement}

Authors thanks Council of Scientific and Industrial Research (CSIR), Government of India for the financial support (File No. (09/844(0046)/2018-EMR-I)). Authors thank Dr. C. H. Cheng of National Taiwan Normal University, Taiwan, and Dr. Uma Mahendra Kumar, Vellore Institute of Technology, Vellore, India.

\section{Declarations}

\section{Funding statement:}

No funding source information is available.

\section{Conflict of Interest:}

There is no conflict of Interest

\section{Author contributions:}

Kadiyam Rajshekar contributed to the development of Comprehensive Density of State model for oxide semiconductors and applied the model on Thin film transistor of various oxide semiconductors through numerical simulations. D Kannadassan has supervised and supported the research works with Kadiyam Rajshekar.

Availability of data and material:

Not applicable

Compliance with ethical standards:

Not applicable

Consent to participate:

Not applicable

\section{Consent for Publication:}

Not applicable 


\section{References}

[1] Fortunato E, Barquinha P, Martins R (2012) Oxide semiconductor thin-film transistors: A review of recent advances. Adv Mater 24:2945-2986. https://doi.org/10.1002/adma.201103228

[2] Hosono H, Yasukawa M, Kawazoe H (1996) Novel oxide amorphous semiconductors: Transparent conducting amorphous oxides. J Non Cryst Solids 203:334-344. https://doi.org/10.1016/0022-3093(96)00367-5

[3] The Magic of Transparent Technology - Pro Display. https://prodisplay.com/the-magic-oftransparent-technology/. Accessed 28 Mar 2020

[4] Nomura K, Ohta H, Takagi A, et al (2004) Room-temperature fabrication of transparent flexible thin-film transistors using amorphous oxide semiconductors. Nature 432:488-492. https://doi.org/10.1038/nature03090

[5] Lim W, Jang JH, Kim SH, et al (2008) High performance indium gallium zinc oxide thin film transistors fabricated on polyethylene terephthalate substrates. Appl Phys Lett 93:082102. https://doi.org/10.1063/1.2975959

[6] Chopra KL, Major S, Pandya DK (1983) Transparent conductors-A status review. Thin Solid Films 102:1-46

[7] Lewis BG, Paine DC (2000) Applications and processing of transparent conducting oxides. MRS Bull 25:22-27. https://doi.org/10.1557/mrs2000.147

[8] Le Y, Shao Y, Xiao X, et al (2016) Indium-Tin-Oxide Thin-Film Transistors With In Situ Anodized $\$ \backslash$ mathrm $\left\{\mathrm{Ta} \_\{2\} \mathrm{O}_{-}\{5\}\right\} \$$ Passivation Layer. IEEE Electron Device Lett 37:603-606. https://doi.org/10.1109/LED.2016.2548785

[9] Cho MH, Seol H, Yang H, et al (2018) High-Performance Amorphous Indium Gallium Zinc Oxide Thin-Film Transistors Fabricated by Atomic Layer Deposition. IEEE Electron Device Lett 39:688-691. https://doi.org/10.1109/LED.2018.2812870

[10] Martins R, Nathan A, Barros R, et al Complementary metal oxide semiconductor technology with and on paper. Adv Mater 23:4491-4496. https://doi.org/10.1002/adma.201102232

[11] Nandy S, Banerjee A, Fortunato E, Martins R (2013) A Review on Cu2O and CuBased p-Type Semiconducting Transparent Oxide Materials: Promising Candidates for New Generation Oxide Based Electronics. Rev Adv Sci Eng 2:273-304. https://doi.org/10.1166/rase.2013.1045

[12] Hogarth CA (1951) Hall constant of cadmium oxide [3]. Nature 167:521-522. https://doi.org/10.1038/167521a0

[13] Cohen MH, Fritzsche H, Ovshinsky SR Simple band model for amorphous semiconducting alloys. Phys Rev Lett 22:1065-1068. https://doi.org/10.1103/PhysRevLett.22.1065

[14] Davis EA, Mott NF (1970) Conduction in non-crystalline systems V. Conductivity, optical absorption and photoconductivity in amorphous semiconductors. Philos Mag 22:903-922. https://doi.org/10.1080/14786437008221061

[15] Nwachuku A, Kuhn M (1968) Tunneling into amorphous germanium films. Appl Phys Lett 12:163-165. https://doi.org/10.1063/1.1651936 
[16] Leenheer AJ, Perkins JD, Van Hest MFAM, et al (2008) General mobility and carrier concentration relationship in transparent amorphous indium zinc oxide films. Phys Rev B - Condens Matter Mater Phys 77:1-5. https://doi.org/10.1103/PhysRevB.77.115215

[17] Hosono H, Kikuchi N, Ueda N, Kawazoe H Working hypothesis to explore novel wide band gap electrically conducting amorphous oxides and examples. J Non Cryst Solids 198-200:165-169. https://doi.org/10.1016/0022-3093(96)80019-6

[18] Robertson J (2008) Disorder and instability processes in amorphous conducting oxides. Phys Status Solidi Basic Res 245:1026-1032. https://doi.org/10.1002/pssb.200743458

[19] Sallis S, Butler KT, Quackenbush NF, et al (2014) Origin of deep subgap states in amorphous indium gallium zinc oxide: Chemically disordered coordination of oxygen. Appl Phys Lett 104:. https://doi.org/10.1063/1.4883257

[20] Körner W, Urban DF, Elsässer C (2013) Origin of subgap states in amorphous InGa-Zn-O. J Appl Phys 114:. https://doi.org/10.1063/1.4826895

[21] Kawazoe H, Yasukawa M, Hyodo H, et al (1997) P-type electrical conduction in transparent thin films of CuAlO2. Nature 389:939-942

[22] Fung TC, Chuang CS, Chen C, et al (2009) Two-dimensional numerical simulation of radio frequency sputter amorphous In-Ga-Zn-O thin-film transistors. J Appl Phys 106:110. https://doi.org/10.1063/1.3234400

[23] Silvaco (2013) Technology Computer Aided Design (TCAD) software

[24] Nam D-W, Cho I-T, Lee J-H, et al (2012) Active layer thickness effects on the structural and electrical properties of p-type $\mathrm{Cu} 2 \mathrm{O}$ thin-film transistors. J Vac Sci Technol BNanotechnology Microelectron 30:. https://doi.org/10.1116/1.4764110

[25] Raebiger H, Lany S, Zunger A (2007) Origins of the p-type nature and cation deficiency in $\mathrm{Cu} 2 \mathrm{O}$ and related materials. Phys Rev B - Condens Matter Mater Phys 76:. https://doi.org/10.1103/PhysRevB.76.045209

[26] Ogo Y, Hiramatsu H, Nomura K, et al (2009) Tin monoxide as an s-orbital-based p-type oxide semiconductor: Electronic structures and TFT application. Phys status solidi 206:2187-2191. https://doi.org/10.1002/pssa.200881792

[27] Kohn W, Sham LJ (1965) Self-consistent equations including exchange and correlation effects. Phys Rev 140:A1133. https://doi.org/10.1103/PhysRev.140.A1133

[28] Matsuzaki K, Nomura K, Yanagi H, et al (2008) Epitaxial growth of high mobility $\mathrm{Cu} 2 \mathrm{O}$ thin films and application to $\mathrm{p}$-channel thin film transistor. Appl Phys Lett 93:3-6. https://doi.org/10.1063/1.3026539

[29] Rajshekar K, Hsu HH, Kumar KUM, et al (2019) Effect of plasma fluorination in p-type SnO TFTs: Experiments, modeling, and simulation. IEEE Trans Electron Devices 66:1314-1321. https://doi.org/10.1109/TED.2019.2895042

[30] Goltzene A, Schwab C, Wolf HC (1976) Carrier resonance in Cu2O. Solid State Commun 18:1565-1567. https://doi.org/10.1016/0038-1098(76)90394-X

[31] Urbach F (1953) The long-wavelength edge of photographic sensitivity and of the electronic Absorption of Solids [8]. Phys Rev 92:1324. https://doi.org/10.1103/PhysRev.92.1324 
[32] Caraveo-Frescas JA, Nayak PK, Al-Jawhari HA, et al (2013) Record mobility in transparent p-type tin monoxide films and devices by phase engineering. ACS Nano 7:5160-5167. https://doi.org/10.1021/nn400852r

[33] Ogo Y, Hiramatsu H, Nomura K, et al (2012) p-channel thin-film transistor using p-type oxide semiconductor, SnO. 032113:1-4. https://doi.org/10.1063/1.2964197

[34] Chen PC, Chiu YC, Zheng ZW, et al (2017) Influence of plasma fluorination on ptype channel tin-oxide thin film transistors. J Alloys Compd 707:162-166. https://doi.org/10.1016/j.jallcom.2016.11.294

[35] Saji KJ, Mary APR (2015) Tin Oxide Based P and N-Type Thin Film Transistors Developed by RF Sputtering. ECS J Solid State Sci Technol 4:Q101-Q104. https://doi.org/10.1149/2.0091509jss

[36] Togo A, Oba F, Tanaka I, Tatsumi K First-principles calculations of native defects in tin monoxide. Phys Rev B - Condens Matter Mater Phys 74:. https://doi.org/10.1103/PhysRevB.74.195128

[37] Çetin K, Zunger A (2002) Origins of Coexistence of Conductivity and Transparency in SnO 2. 7-10. https://doi.org/10.1103/PhysRevLett.88.095501

[38] Shang ZW, Ma J, Liu WD, et al (2020) Performance Investigation of an n-Type Tin-Oxide Thin Film Transistor by Channel Plasma Processing. IEEE J Electron Devices Soc 8:485-489. https://doi.org/10.1109/JEDS.2020.2986172

[39] Godinho KG, Walsh A, Watson GW (2009) Energetic and electronic structure analysis of intrinsic defects in SnO2. J Phys Chem C 113:439-448. https://doi.org/10.1021/jp807753t 
Figures

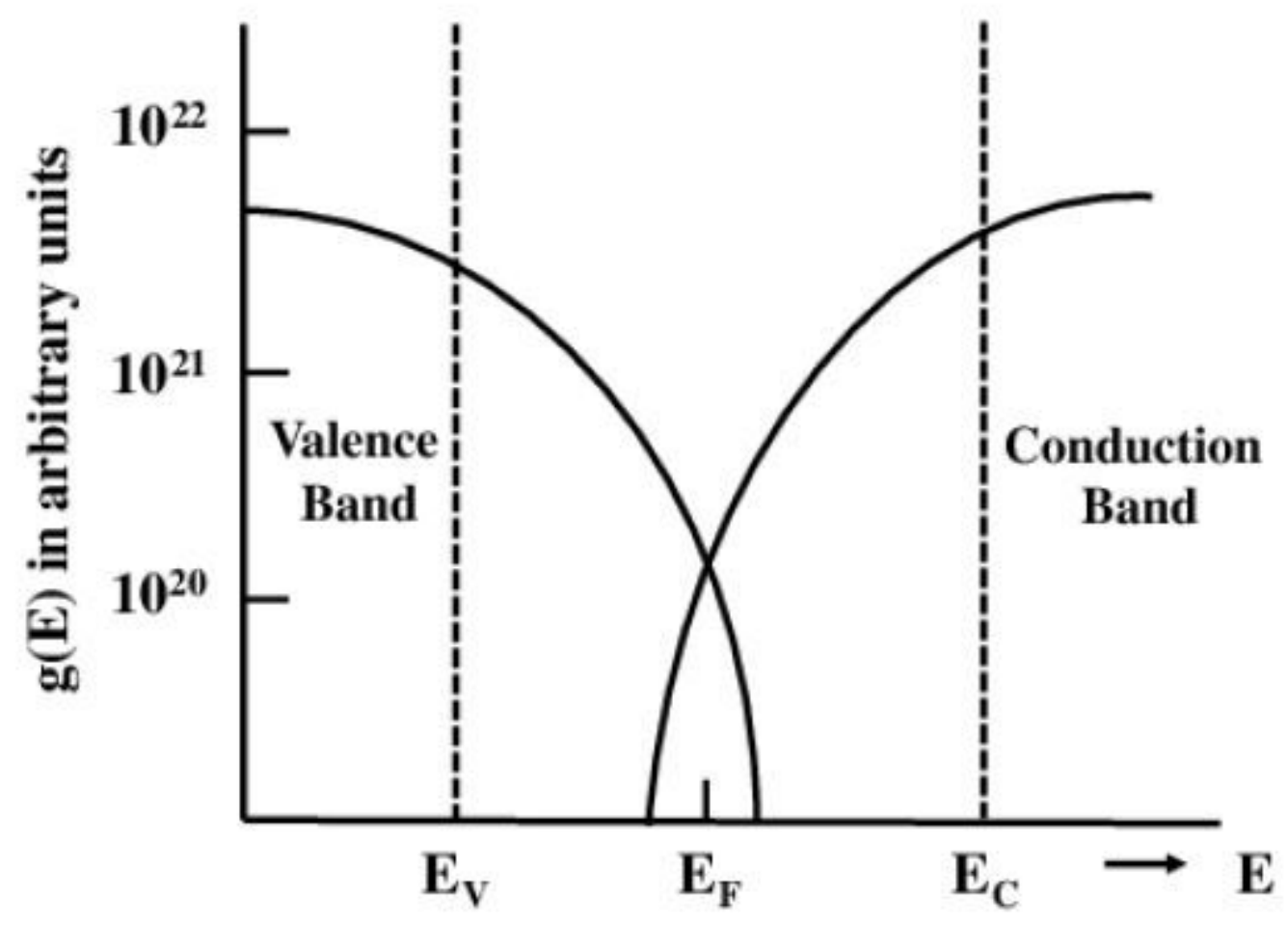

Figure 1

A simple two tail state model for amorphous semiconductors (Cohen Model) [13]

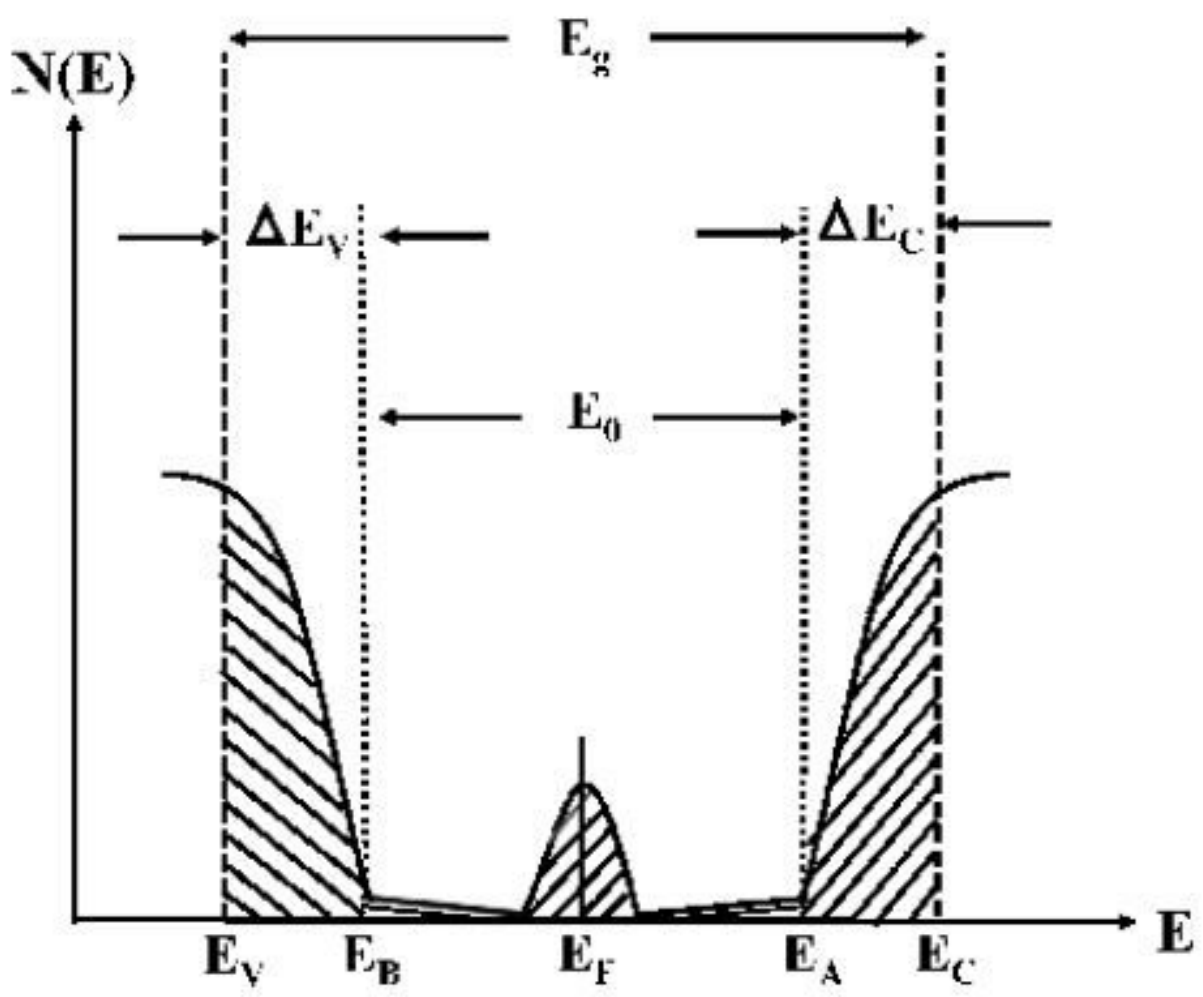


Figure 2

Improvised band model for amorphous semiconductors (Davis model) [14].

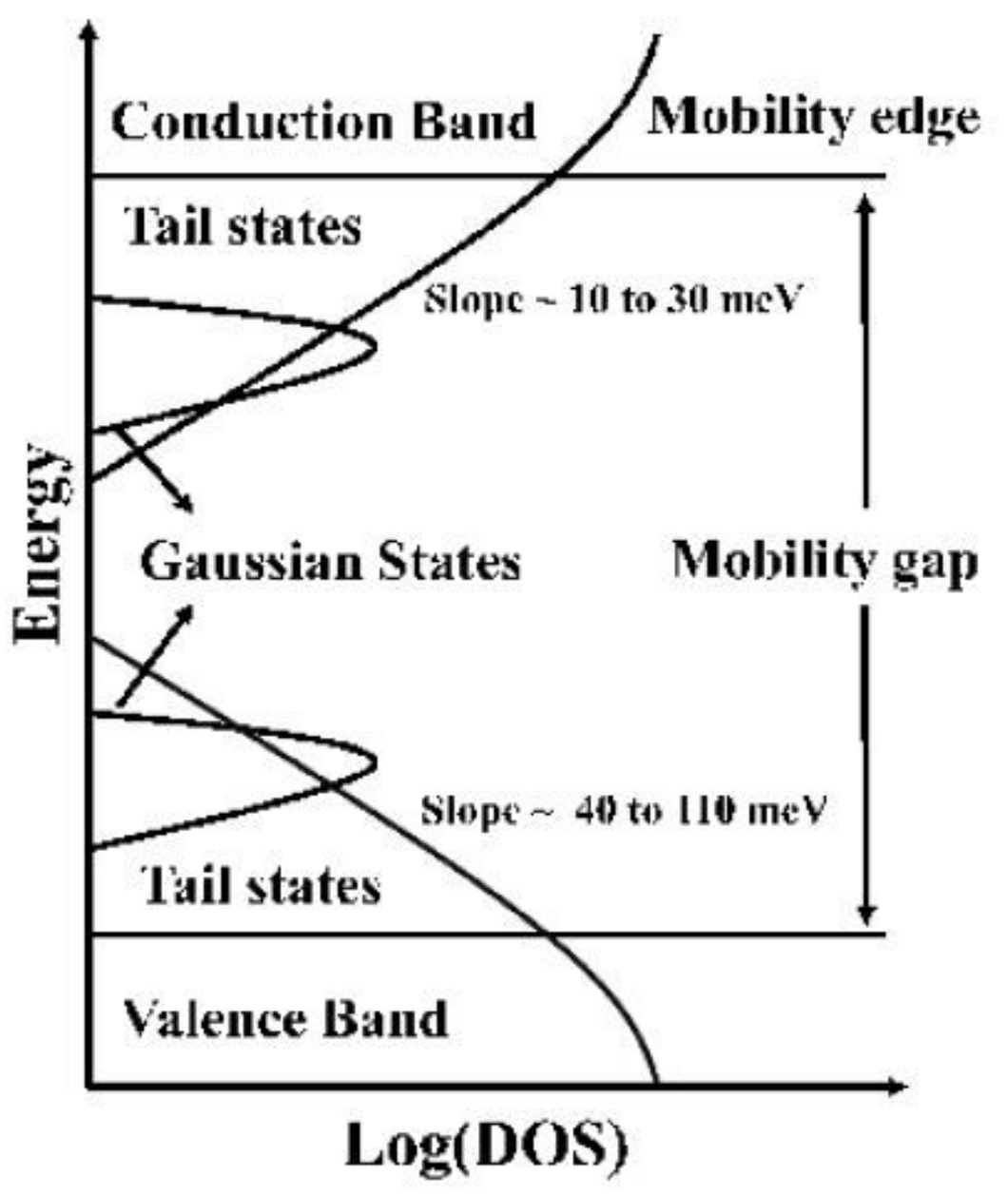

Figure 3

Proposed comprehensive DOS Model for oxide semiconductors 


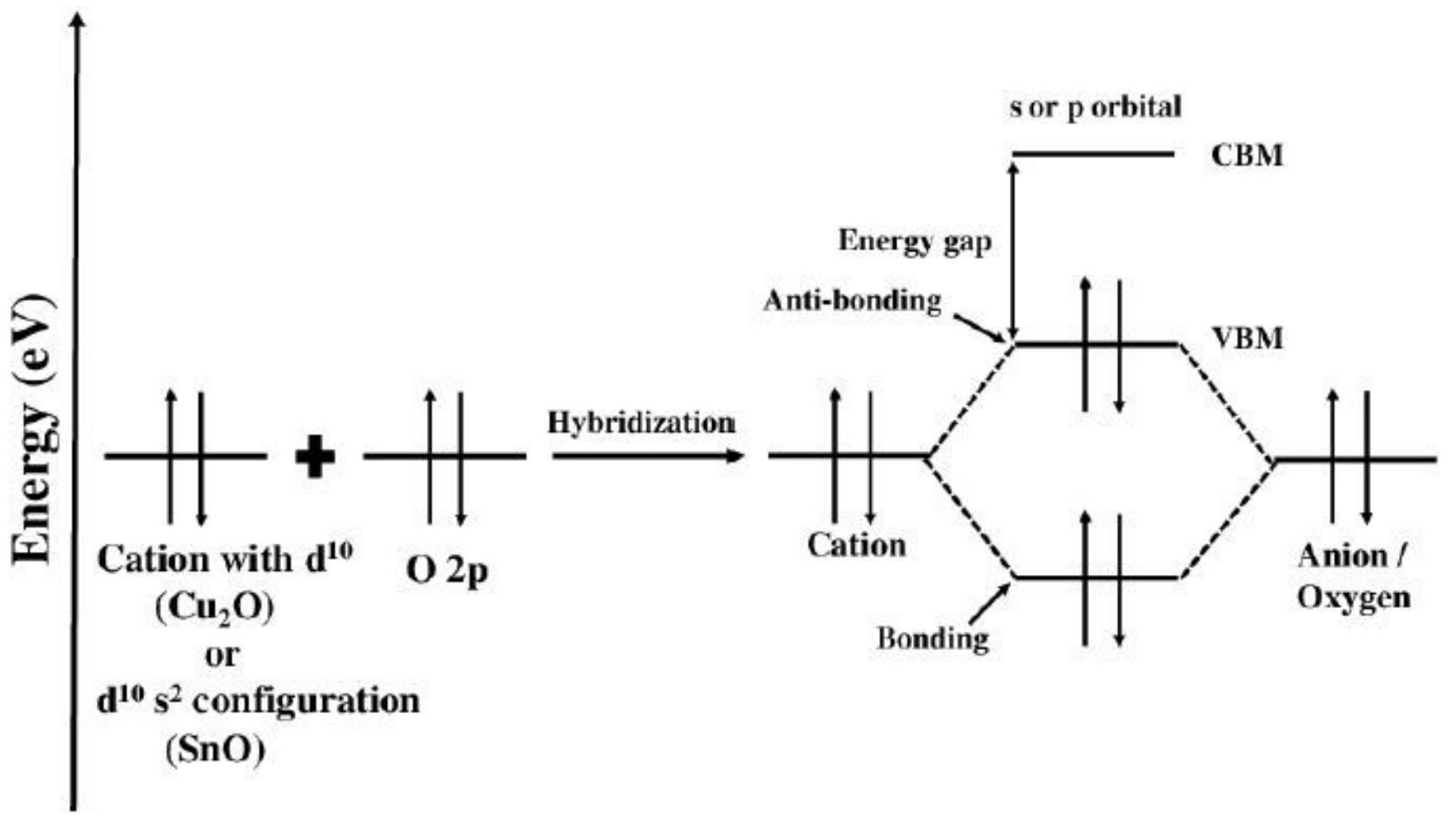

Figure 4

Chemical modulation of Valence Band between closed or pseudo closed metal configuration and an oxide ion [21]. 

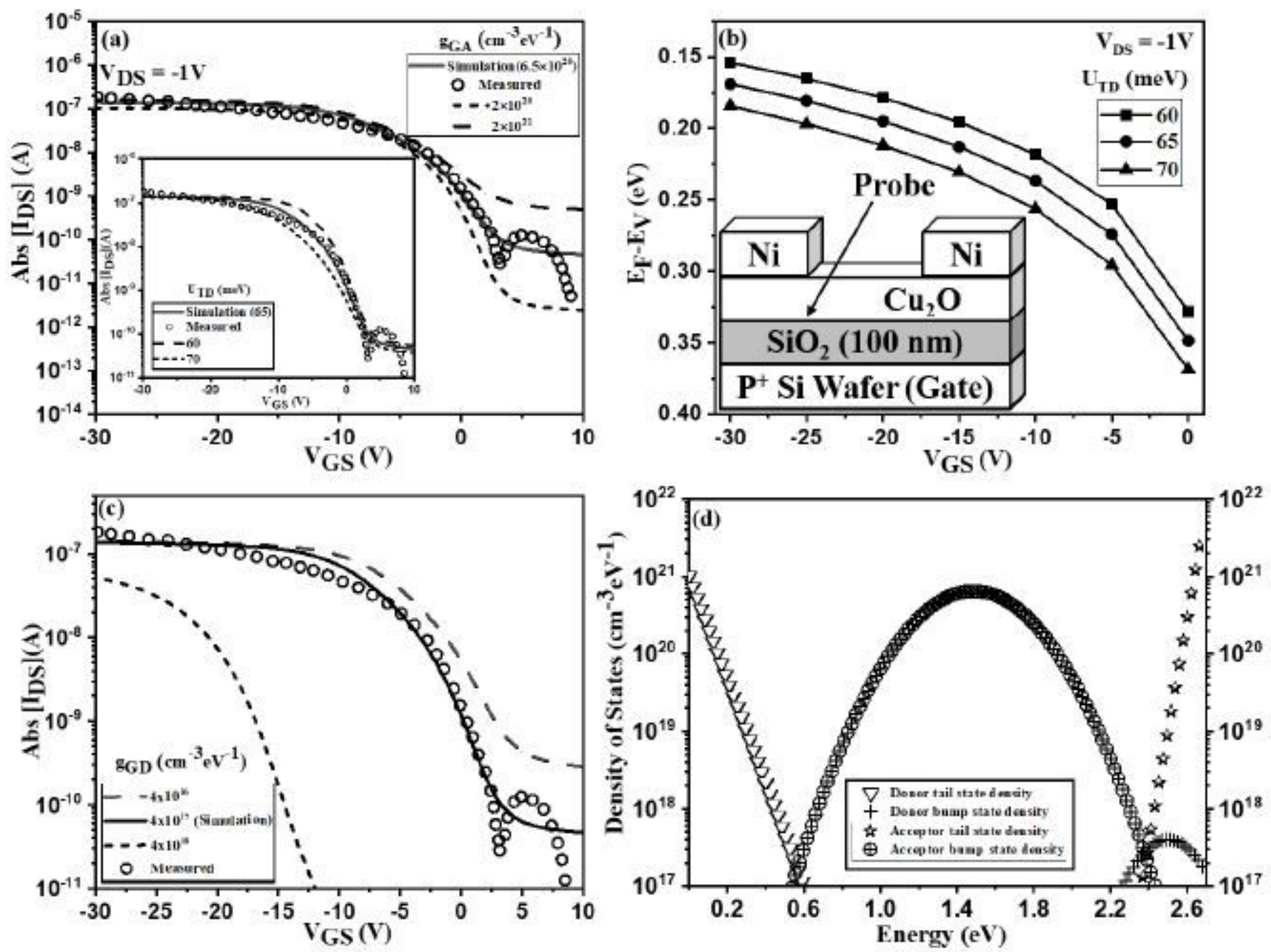

Figure 5

(a) Compatibility of simulated transfer characteristics of Cu2O TFTs for various gGA with measured results (Inset: variation in UTD), (b) Effect of VGS on (EF-EV) at the probe (Inset: Structure of Cu2O TFT), (c) Compatibility of simulated transfer characteristics of Cu2O TFTs for various gGD with measured results (d) Extracted DOS of Cu2O TFT. (Measured data: [24]) 

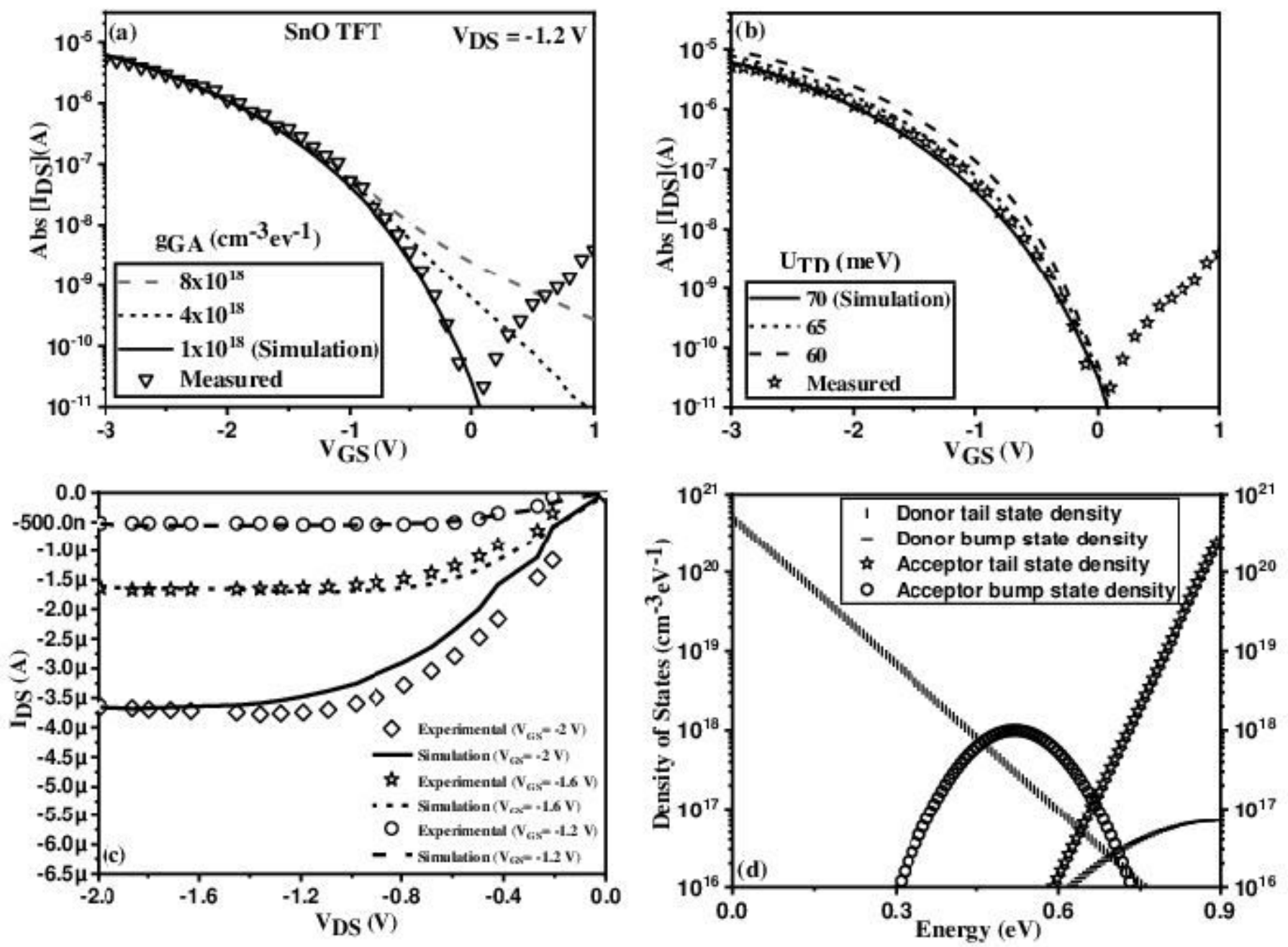

Figure 6

(a) Compatibility of simulated transfer characteristics of SnO TFTs for various gGA with measured results, (b) Compatibility of simulated transfer characteristics of SnO TFTs for various gGD with measured results, (c) Simulated output characteristics with measured results (d) Extracted DOS of SnO TFT. (Measured data: [29]) 

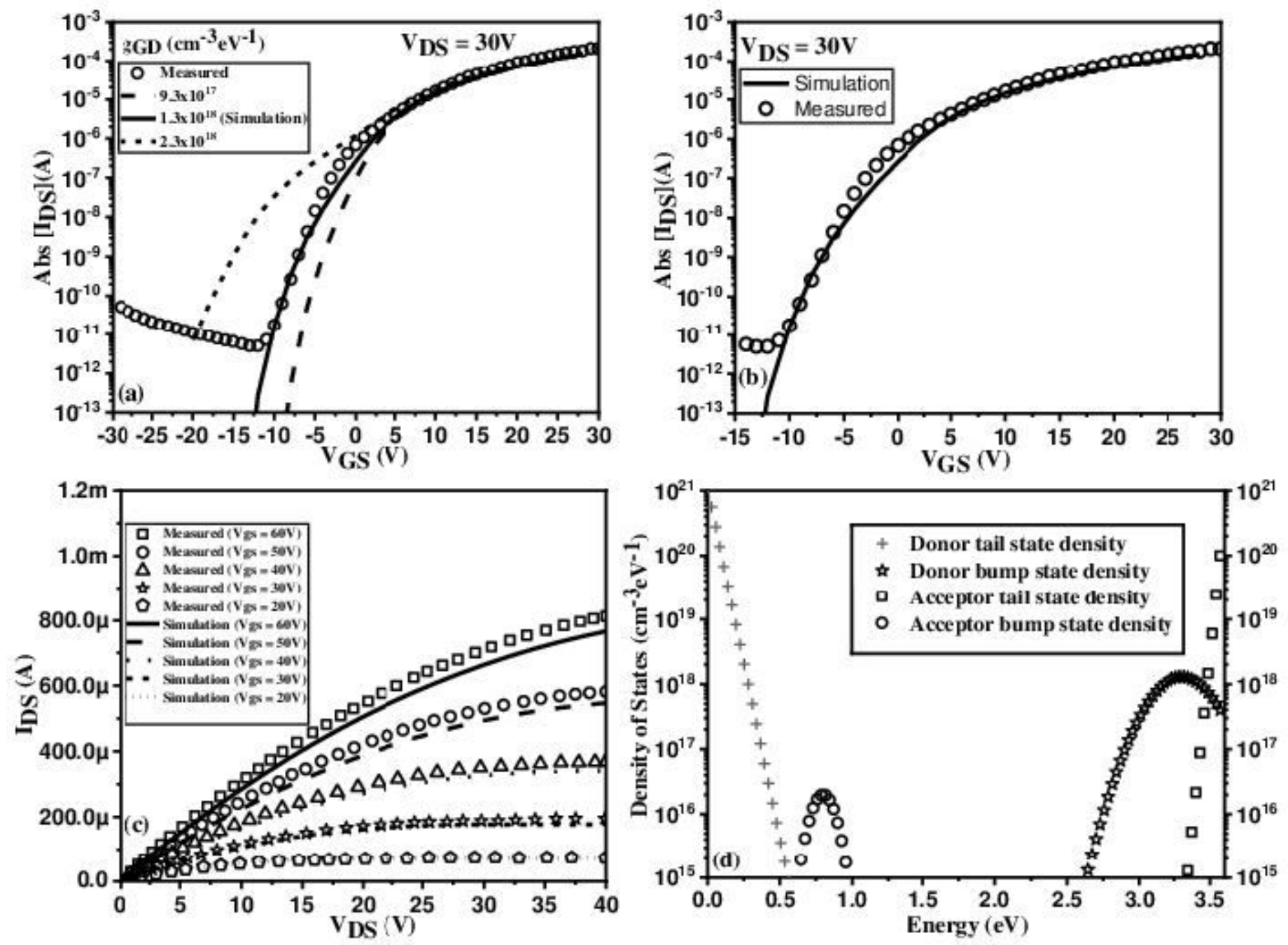

Figure 7

(a) Compatibility of simulated transfer characteristics of SnO2 TFTs for various gGD with measured results, (b) Compatibility of simulated transfer characteristics of SnO2 TFTs for various gGD $=1.3 \times 1018$ cm-3eV-1 with measured results, (c) Simulated output characteristics with measured results (d) Extracted DOS of SnO2 TFT. (Measured data: [35]) 


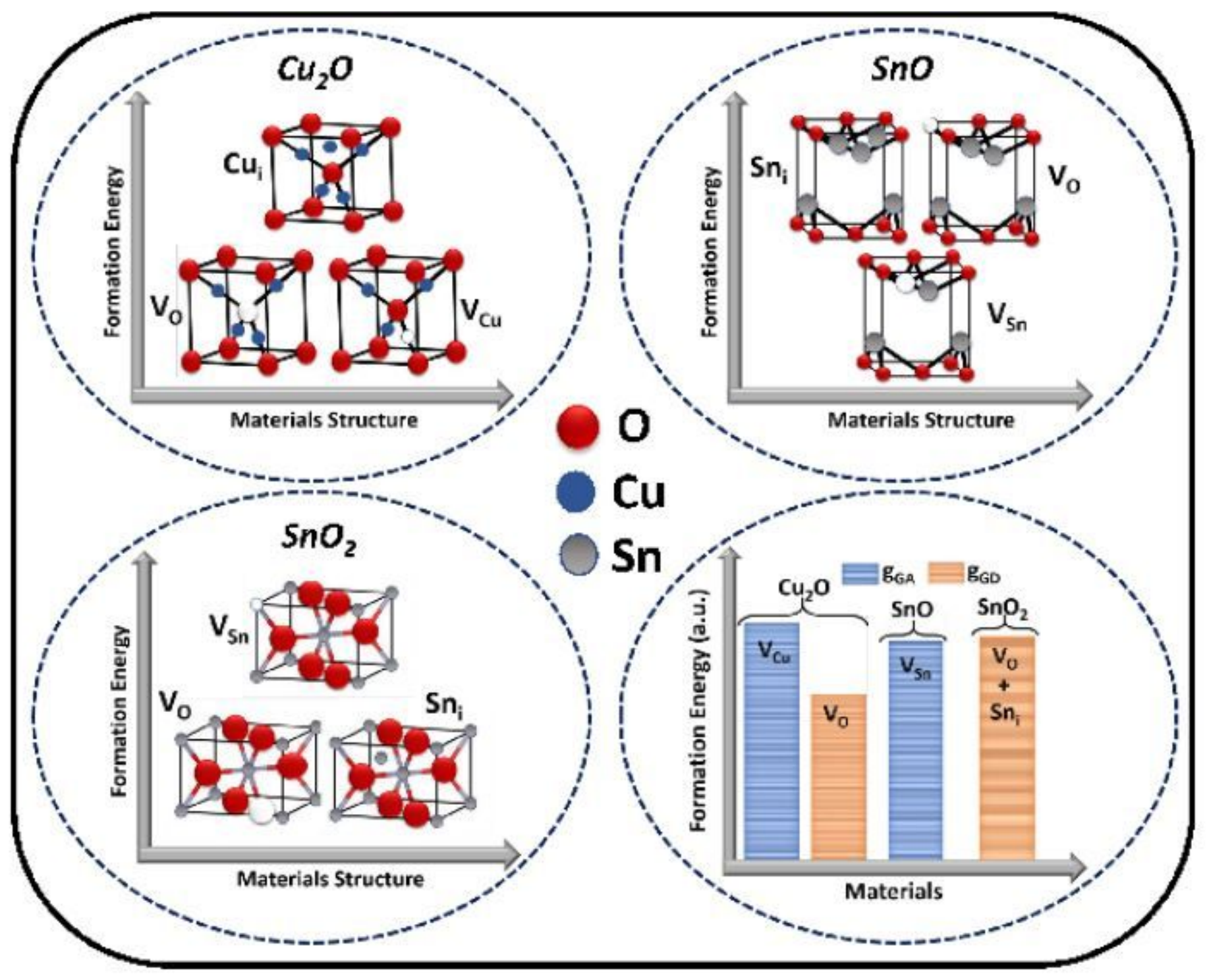

Figure 8

Summary of comprehensive physical model for various oxide semiconductor 